\title{
Diversity and abundance of ammonia-oxidizing prokaryotes in sediments from the coastal Pearl River estuary to the South China Sea
}

\author{
Huiluo Cao $\cdot$ Yiguo Hong $\cdot$ Meng $\mathrm{Li} \cdot$ Ji-Dong Gu
}

Received: 5 April 2011/Accepted: 10 June 2011/Published online: 30 June 2011

(C) The Author(s) 2011. This article is published with open access at Springerlink.com

\begin{abstract}
In the present study the diversity and abundance of nitrifying microbes including ammonia-oxidizing archaea (AOA) and betaproteobacteria (beta-AOB) were investigated, along with the physicochemical parameters potentially affecting them, in a transect of surface sediments from the coastal margin adjacent to the Pearl River estuary to the slope in the deep South China Sea. Nitrifying microbial diversity was determined by detecting the amoA (ammonia monooxygenase subunit A) gene. An obvious community structure shift for both AOA and beta-AOB from the coastal marginal areas to the
\end{abstract}

Electronic supplementary material The online version of this article (doi:10.1007/s10482-011-9610-1) contains supplementary material, which is available to authorized users.

H. Cao · M. Li · J.-D. Gu ( $\bowtie)$

Laboratory of Environmental Microbiology and Toxicology, School of Biological Sciences, The University of Hong Kong, Pokfulam Road, Hong Kong, SAR, People's Republic of China e-mail: jdgu@hkucc.hku.hk

Y. Hong

State Key Laboratory of Oceanography in the Tropics, South China Sea Institute of Oceanography, Chinese Academy of Sciences, 164 Xingang Road West, Guangzhou 510301, People's Republic of China

J.-D. $\mathrm{Gu}$

The Swire Institute of Marine Science, The University of Hong Kong, Shek O, Cape d'Aguilar, Hong Kong, SAR, People's Republic of China slope in the deep-sea was detected, while the OTU numbers of AOA amoA were more stable than those of the beta-AOB. The OTUs of beta-AOB increased with the distance from the coastal margin areas to the slope in the deep-sea. Beta-AOB showed lower diversity with dominant strains in a polluted area but higher diversity without dominant strains in a clean area. Moreover, the diversity of beta-AOB was correlated with $\mathrm{pH}$ values, while no noticeable relationships were established between AOA and physicochemical parameters. Beta-AOB was more sensitive to transect environmental variability and might be a potential indicator for environmental changes. Additionally, the surface sediments surveyed in the South China Sea harboured diverse and distinct AOA and beta-AOB phylotypes different from other environments, suggesting the endemicity of some nitrifying prokaryotes in the South China Sea.

Keywords Ammonia-oxidizing archaea . Ammonia-oxidizing bacteria $\cdot$ South China Sea . Ammonia monooxygenase subunit A (amoA)

\section{Introduction}

Nitrification, the microbial aerobic oxidation of ammonia to nitrate via nitrite plays an important role in the global nitrogen cycle and is the first and ratelimiting step. Besides two distinct monophyletic 
groups of chemolithoautotrophic ammonia-oxidizing bacteria (AOB) (beta- and gamma-proteobacteria), a novel group of archaea (ammonia-oxidizing archaea, AOA) have been proposed recently to be involved in ammonia oxidation (Venter et al. 2004; Schleper et al. 2005). In estuarine and coastal sediments, microbial nitrification may be critical in the benthic nitrogen cycle by regulating nitrification and denitrification (Francis et al. 2005; Caffrey et al. 2007) and coupling with anammox (anaerobic ammonium oxidation) activity (Coolen et al. 2007; Lam et al. 2007). Studies have been conducted to investigate the community structure and abundance of nitrifying prokaryotes in estuaries (Francis et al. 2005; Beman and Francis 2006; Freitag et al. 2006; Bernhard et al. 2010; Wankel et al. 2011). Because estuaries and the intertidal sediments experience large fluctuations in hydrological activity, nutrient and chemical conditions, nitrifiers might respond to these changes, resulting in shifts of community structure and responses to the environmental changes. However, the intermediate area between marginal coasts to the deep-sea areas has not received enough attention, especially in the coastal area of the Western Pacific which is in the tropical and subtropical zones and is adjacent to several major estuaries of the region. For example, the Pearl River (Zhujiang), close to the northern part of the South China Sea (SCS), is the second largest river in China based on the discharge volume of water to the SCS through sub-estuaries (Huang et al. 2003). In the past two decades, the Pearl River estuary, one of the most complex estuarine systems in the world, has received a high loading of anthropogenic nutrients from one of the most rapidly developing areas of the world economy (Callahana et al. 2004), resulting in distinct differences between conditions in the Pearl River estuary and in the adjacent SCS ocean, e.g., an anthropogenic pollution gradient from extremely eutrophic in the Pearl River estuary to oligotrophic in the vast area of the northern SCS (Cai and Jiao 2008). Although Cai and Jiao (2008) recently surveyed the nitrate assimilation community in this area through amplifying the nas $A$ gene, information about other microbes closely associated with the nitrogen cycles, e.g., nitrifying prokaryotes (AOA and AOB), is still scarce. Moreover, most former studies were confined to the temperate and subtropical coast of the East Pacific Ocean, while others focused on the estuarine area.
The shift in microbial diversity from coastal area to the deep-sea has not been reported, especially in the western Pacific.

Selective species or lineages of nitrifying microbes including AOA and beta-AOB may be confined to a narrow habitat while others may tolerate to a much wider range of environmental conditions. For example, in Bahía del Tóbari, a hyper-nutrified estuary receiving substantial amounts of ammonium from agricultural runoff, bacterial amoA gene clone libraries were dominated by a few Nitrosomonas-like sequence types which were widely distributed, whereas AOA diversity showed significant variation in both richness and community composition (Beman and Francis 2006). In the Westerschelde estuary, the dominant beta-AOB groups were members of the genus Nitrosomonas (which were abundant in the brackish sites) and some lineages of the genus Nitrosospira (which were present at the marine sites) (Sahan and Muyzer 2008). Such information indicates there are significant differences in habitat requirement and potentially niche range between AOA and beta-AOB. To date, few factors have been confirmed to affect the microbial community structure of ammonia-oxidizing prokaryotes. Salinity has been shown to be an important factor to shape the community structure of nitrifying prokaryotes (Mosier and Francis 2008; Santoro et al. 2008). Besides this, the distinct seasonal variations of temperature, irradiance and river discharge also affect the microbial community structure of nitrifying microbes in estuaries. Moreover, the abundance of ammonia-oxidizing prokaryotes also changes with the gradient of some environmental parameters. For instance, Santoro et al. (2008) detected shifts in relative abundance of ammonia-oxidizing bacteria and archaea across physicochemical gradients in a subterranean estuary. Although salinity has been suggested to be an important factor to determine the diversity and abundance of AOA and beta-AOB (Mosier and Francis 2008; Santoro et al. 2008), no single factor is likely to shape the whole community structure and abundance of nitrifying microbes and it is possible that combined environmental factors might be collectively responsible for the diversity and abundance of nitrifying prokaryotes observed.

Surface sediments across a six-site transect along the continental shelf to the slope transect in the SCS with almost constant salinity were examined in this 
study. The amoA gene was employed as a functional genetic marker to detect community structure and spatial distribution of AOA and beta-AOB and the amoA gene abundance was measured using quantitative PCR (q-PCR). Finally, the main potential physicochemical contributors to the diversity and abundance of AOA and beta-AOB were determined at this study site.

\section{Materials and methods}

Sampling and molecular experiments

Sampling was conducted aboard the R/V Shiyan 3 during a South China Sea Open Cruise in 2008. Six surface sedimentary samples along the coast to the slope of the SCS were selected (Supplementary Fig. S1). After the sediment cores were obtained on board, air exposed outer surfaces were removed using a sterilized stainless steel knife and the central core was placed into plastic bags and stored at $-20^{\circ} \mathrm{C}$ immediately. The environmental parameters $(\mathrm{pH}$, depth, temperature etc.) were monitored in situ and other chemical parameters (e.g., the concentrations of ammonium, nitrite and nitrate) in the sediments were measured in the laboratory using an autoanalyzer according to standard techniques (ASTM D3590-89B and D3867-99B) as described previously (Cao et al. 2011a, b; Li et al. 2011).

Two pairs of specific amoA PCR primers (ArchamoAF: 5'-STAATGGTCTGGCTTAGACG-3' and Arch-amoAR: 5'-GCGGCCATCCATCTGTATGT-3' for AOA; amoA-1F: 5'-GGGGTTTCTACTGGTG GT-3' and amoA-2R: 5'-CCCCTCKGSAAAG CCTTCTTC $-3^{\prime}$ for beta-AOB) were employed to generate PCR products (635 bps and 491 bps for AOA and beta-AOB, respectively) from extracted total genomic DNA, as described previously (Cao et al. 2011a, b; Li et al. 2011). All PCR reactions (50 $\mu$ l volume) were conducted using the following reagents: $1 \mu \mathrm{l}$ template DNA (30-100 ng $\left.\mu \mathrm{l}^{-1}\right)$, $20 \mathrm{pmol}$ of each primer, $1.25 \mathrm{U}$ of Taq polymerase, $200 \mu \mathrm{M}$ each dNTP, $150 \mathrm{mM} \mathrm{MgCl}_{2}$ and $1 / 10$ volume of $10 \times \mathrm{PCR}$ buffer. A thermocycler program consisting of the following steps was used: $5 \mathrm{~min}$ at $94^{\circ} \mathrm{C}$, then 35 cycles of $45 \mathrm{~s}$ at $94^{\circ} \mathrm{C}$, then $45 \mathrm{~s}$ at annealing temperature $\left(53^{\circ} \mathrm{C}\right.$ for AOA and $55^{\circ} \mathrm{C}$ for beta-AOB) and $45 \mathrm{~s}$ extension at $72^{\circ} \mathrm{C}$, with the last cycle run at $72^{\circ} \mathrm{C}$ for $7 \mathrm{~min}$ as the terminal extension. Purified PCR products were inserted into the T-vector (Takara, Hong Kong) for constructing clone libraries and then selected positive clones were sequenced using ABI 3730XL sequencer (ABI, Applied Biosystems). The abundance (copy numbers) of archaeal and bacterial amoA genes in the samples were determined with the specific primers above by quantitative PCR (q-PCR) using the same volume of each reaction mixture, including 1-10 ng template DNA, $0.2 \mathrm{mg} / \mathrm{ml}$ BSA, $200 \mathrm{nM}$ of each primer and $12.5 \mu \mathrm{l}$ of SYBR Premix (Takara, Hong Kong). The protocol used was according to Chen et al. (2008). All reactions were run in triplicate. A serial dilution of plasmids containing clone 704A-6 for AOA and clone 704B-6 for betaAOB were separately used as standards.

Phylogenetic and statistical analyses

All of the amoA gene sequences determined were imported into MEGA 4.1 (Tamura et al. 2007) and translated into amino acid sequences to construct alignment files using Clustal X 1.81 in combination with the most similar AOA and beta-AOB deduced AmoA amino acid sequences retrieved from GenBank. Phylogenetic trees were constructed from a total of 103 deduced AOA AmoA protein sequences (59 sequences from this study) with the final length of 209 aa and 74 deduced beta-AOB AmoA protein sequences ( 35 sequences from this study) with the final length of 158 aa using neighbor-joining criterion in MEGA 4.1 (Tamura et al. 2007) with 1000 bootstrap tests.

Rarefaction analysis and two additional nonparametric richness estimators, Chao1, Simpson and the Shannon diversity index were performed in DOTUR based on a 5\% gene sequence distance cutoff (Schloss and Handelsman 2006). Principal coordinates analyses (PCoA) and Jackknife Environment Clusters analyses were conducted using online software (UniFrac, http://bmf2.colorado.edu/unifrac/) for comparison of the microbial communities using phylogenetic information (Lozupone et al. 2006). Environment clusters trees were projected in MEGA 4.1 (Tamura et al. 2007). The relationships between physicochemical characteristics and those diversity parameters and abundance of amoA gene for AOA and beta-AOB were determined through calculation of Pearson moment correlations in Microsoft Excel. 


\section{Results}

Environmental parameters

The environmental features of sediments at the six sites are shown in Supplementary Table S1. The seawater depth ranged from $40 \mathrm{~m}$ at the shallowest site 709 to $2370 \mathrm{~m}$ at the deepest site 702 . The temperature was in clear contrast with the seawater depth and it decreased with the depth. The lowest surface sediment temperature was $2.9^{\circ} \mathrm{C}$ at site 702 , whilst the highest was $21.3^{\circ} \mathrm{C}$ at site 709 with the shallowest depth. Salinity showed minimal fluctuation among all six sites. The $\mathrm{pH}$ value was the lowest at site 702 and the highest at site 708. The concentration of $\mathrm{NH}_{4}^{+}$peaked at site 707 and, except for this site, the concentration of $\mathrm{NH}_{4}^{+}$showed a decreasing trend from the continental shelf adjacent to Pearl River estuary discharge to the slope of the SCS. The concentration of $\mathrm{NO}_{3}{ }^{-}$was the highest at site 707 , while $\mathrm{NO}_{2}{ }^{-}$was the highest at site 704 .

Diversity and richness of amoA gene sequences in the surface sediments

Overall, a total of 88 and 27 OTUs based on amoA gene sequences were recovered for archaea and bacteria, respectively, based on a $5 \%$ amoA gene sequence distance cutoff. Within each clone library, the numbers of OTU did not vary much for AOA but they increased for AOB from the continental shelf to the slope in the deep-sea corresponding to an increase of depth, notably with the highest diversity of beta$\mathrm{AOB}$ at site 702 (Table 1). The Chao1 diversity estimator, a conservative one for species richness, showed higher variability with beta-AOB than AOA (Table 1) at a $5 \%$ identity difference. The Shannon
Fig. 1 Phylogenetic tree based on deduced archaeal AmoA protein sequences from sediment samples from a profile along the coastal shelf to the slope in South China Sea. The consensus phylogenetic tree was constructed using the neighbor-joining method. The numbers at the nodes are percentages represent of the credible values above 50 on the basis of 1000 times bootstrap test. Branch lengths were scaled by sequence differences. Sequences from this study are in bold and the information bracketed following the sequence names indicated other sequences obtained

index, which takes into account both species richness and evenness, also showed a similar variability difference between $\mathrm{AOA}$ and beta-AOB at a $5 \%$ identity difference (Table 1). Both the Chaol diversity estimator and the Shannon diversity index indicated that beta-AOB diversity was significantly correlated with $\mathrm{pH}$ values.

Phylogenetic diversity of deduced AmoA protein sequences in the surface sediments

The phylogenetic tree based on deduced archaeal AmoA protein indicated that the derived sequences were affiliated solely with sequences in marine water column/sediment clade and no sequences were associated with the soil/sediment clade detected in this phylogenetic tree (Fig. 1). However, a few subclades could be further delineated within the marine water/ sediment clade (Fig. 1). Two subclades, Clades WA and WB, consisted of estuarine sequences from GenBank, e.g., Changjiang Estuary (Dang et al. 2008), subterranean estuary (Santoro et al. 2008), hyper-nutrified subtropical estuary (Beman and Francis 2006), Bahia del Tobari Mexico Gulf (Francis et al. 2005), Elkhorn Slough CA Hudsons Lan (Francis et al. 2005), tropical estuarine sediments on the central west coast of India (Singh et al. 2010). Except for a few sequences from site 704 and only

Table 1 Diversity and richness indices of the $a m o A$ gene sequences from the clone libraries

\begin{tabular}{|c|c|c|c|c|c|c|c|c|c|c|}
\hline \multirow[t]{2}{*}{ Sample } & \multicolumn{2}{|c|}{ Clone number } & \multicolumn{2}{|l|}{ OTUs } & \multicolumn{2}{|c|}{ Simpson index } & \multicolumn{2}{|c|}{ Shannon index } & \multicolumn{2}{|c|}{ Chaol index } \\
\hline & $\mathrm{AOA}$ & $\mathrm{AOB}$ & $\mathrm{AOA}$ & $\mathrm{AOB}$ & $\mathrm{AOA}$ & $\mathrm{AOB}$ & $\mathrm{AOA}$ & $\mathrm{AOB}$ & $\mathrm{AOA}$ & $\mathrm{AOB}$ \\
\hline 702 & 60 & 39 & 19 & 11 & 0.11 & 0.12 & 2.50 & 2.15 & 22 & 12 \\
\hline 704 & 61 & 41 & 23 & 9 & 0.07 & 0.24 & 2.80 & 1.63 & 34 & 19 \\
\hline 706 & 54 & 41 & 19 & 5 & 0.08 & 0.40 & 2.61 & 1.05 & 21 & 5 \\
\hline 707 & 52 & 44 & 18 & 4 & 0.09 & 0.43 & 2.57 & 0.94 & 20 & 4 \\
\hline 708 & 68 & 31 & 20 & 2 & 0.07 & 0.94 & 2.66 & 0.14 & 29 & 2 \\
\hline 709 & 55 & 30 & 19 & 5 & 0.05 & 0.29 & 2.77 & 1.34 & 21 & 5 \\
\hline
\end{tabular}




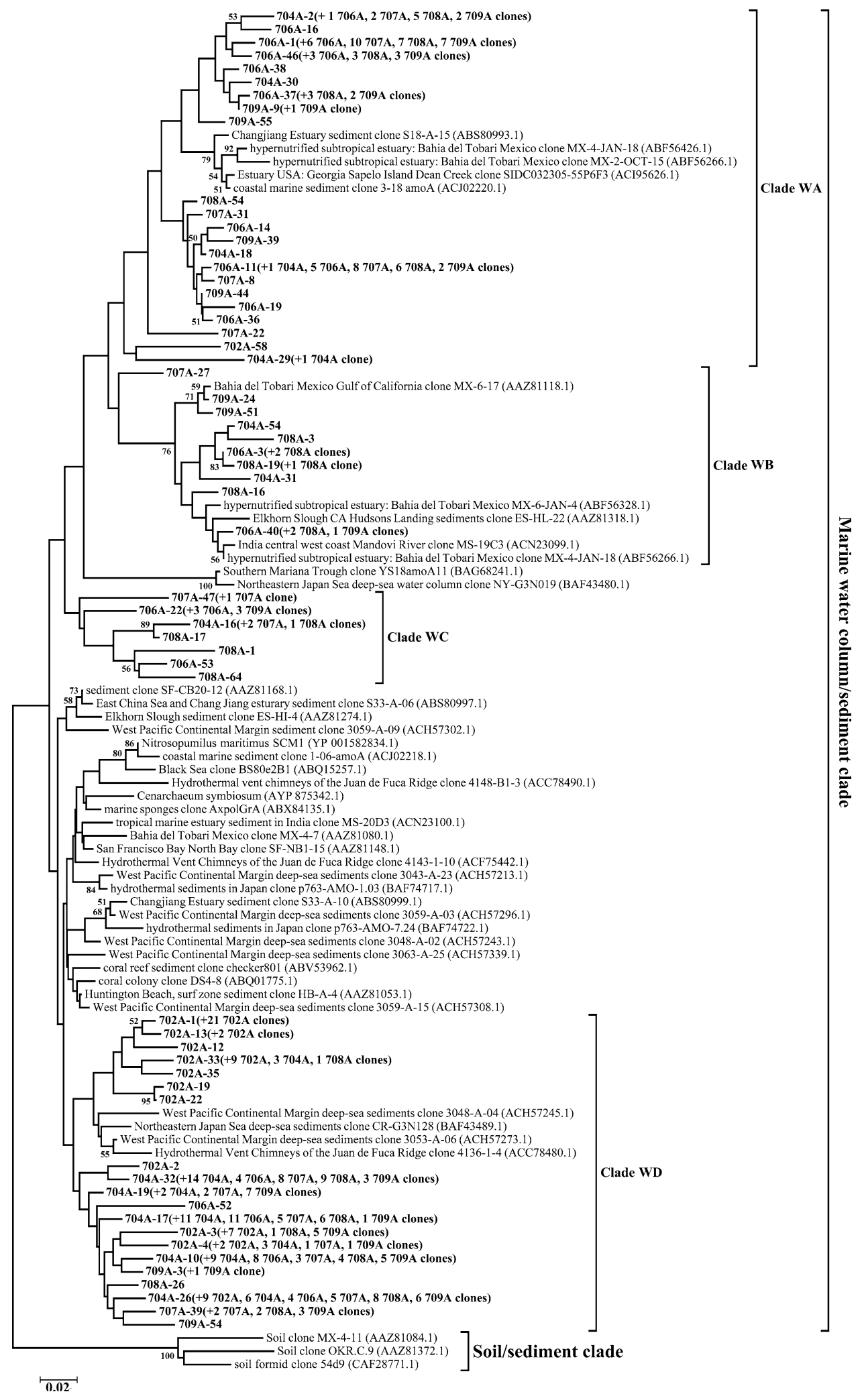


Fig. 2 Phylogenetic tree constructed from deduced bacterial AmoA protein sequences retrieved from sediment samples from a profile along the coastal shelf to the slope in South China Sea based on the neighbor-joining criterion. The numbers near the nodes represent of the credible values $(>50)$ calculated from 1000 times bootstrap test. Branch lengths correspond to the amino acid differences. Sequences from this study are in bold and the information bracketed following the sequence names indicated other sequences obtained

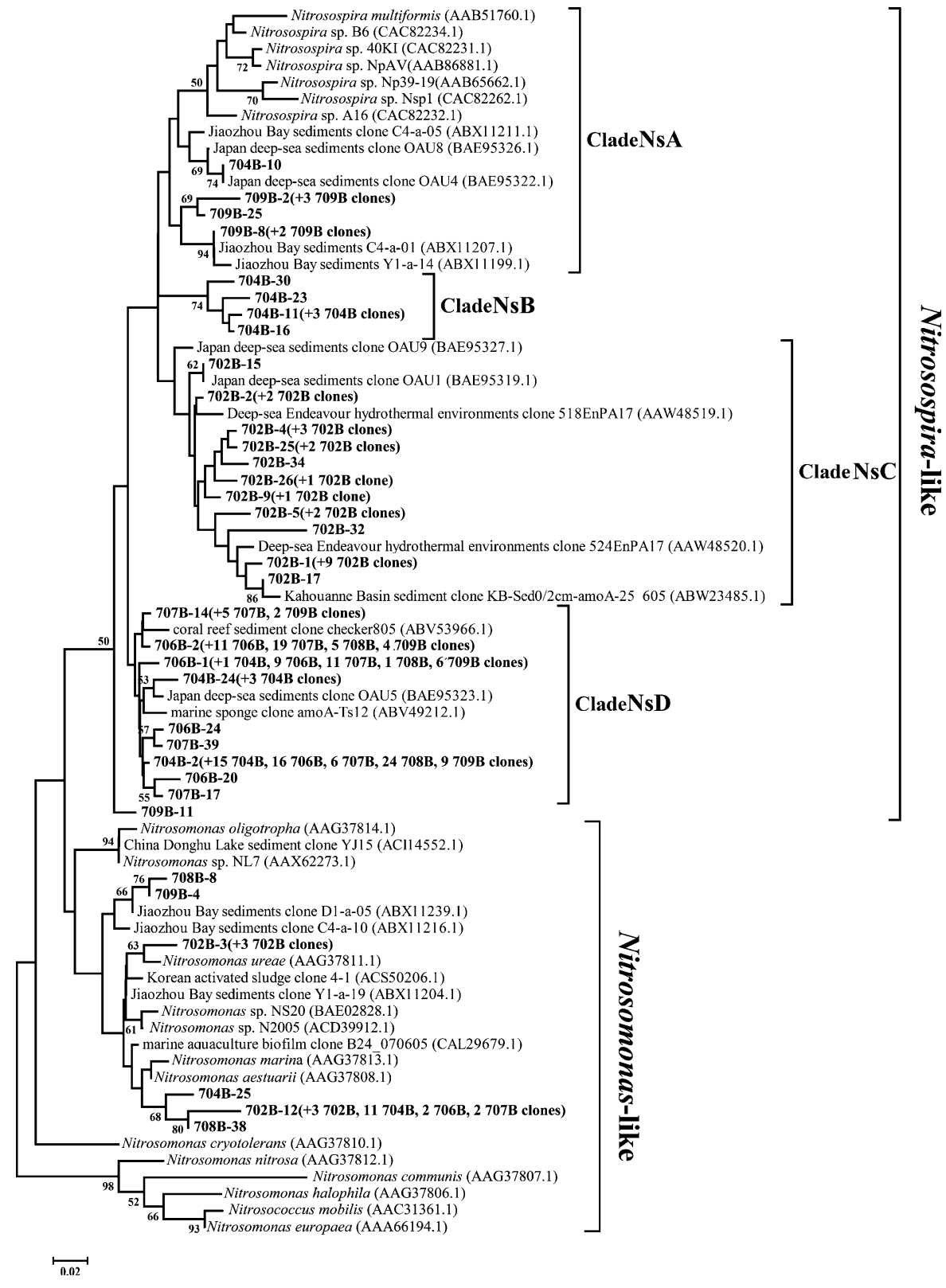

one from site 702, most sequences affiliated with these two subclades were from sites 706, 707, 708 and 709 , which are coastal samples close to the estuary. Clade WD contains sequences from deep-sea sediments, e.g., the tropical West Pacific Continental Margin sediment (Dang et al. 2009), Northeastern Japan Sea deep-sea sediments (Nakagawa et al. 2007) and hydrothermal vent chimneys of the Juan de Fuca Ridge (Wang et al. 2009). Most of the sequences affiliated with this subclade are from sites 702 and 704. Only a few sequences from sites 706, 707, 708,
709 clustered together and formed Clade WC, sharing $<92 \%$ identity with others retrieved from GenBank at the deduced amino acid level, notably 708A-1 sharing $<85 \%$ identity with sequences from hydrothermal vent of Juan de Fuca Ridge (the main endeavour segment, Mothra field) (Wang et al. 2009) and from Changjiang estuary, e.g., S7-A-19, S8-A-10 (Dang et al. 2008). It is clear that phylogenetically dominant lineages form a transitory distribution pattern along the transect from the estuarine-related site 709 to the deep-sea related site 702 in this study. 

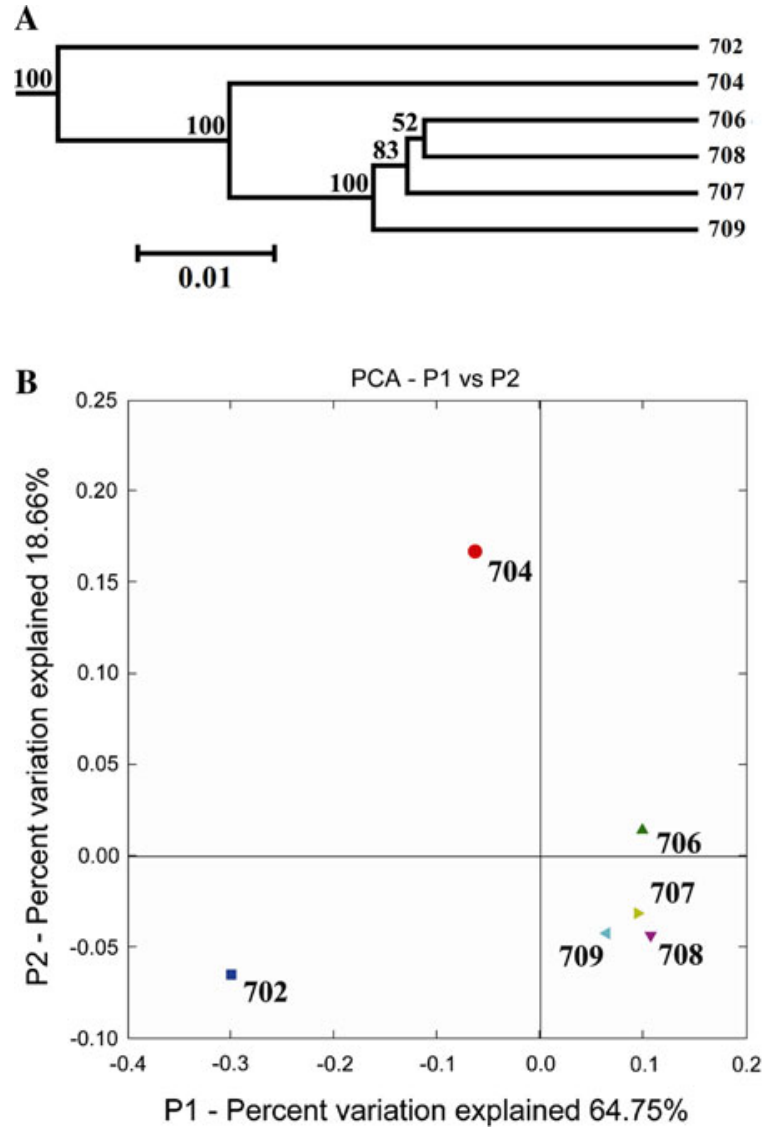

Fig. 3 Jackknife Environment Clusters (UPGMA algorithm with 100 replicates, Jackknife supporting test) and Principal coordinate analysis (PCoA) analyses for amoA gene assemblages of $\mathrm{AOA}$ and beta-AOB obtained from the online

Two distinct clades, of Nitrosospira-like and Nitrosomonas-like sequences, were present in the deduced bacterial AmoA protein phylogenetic tree (Fig. 2). Most of them were affiliated to Nitrosospiralike lineages (199 out of 226), while only 27 sequences grouped with Nitrosomonas-like lineages. In the Nitrosomonas-like clade, two sequences were clustered with those from sediments of Jiaozhou Bay (Dang et al. 2010) while others closely related to some pure cultures, including Nitrosomonas ureae, Nitrosomonas marina and Nitrosomonas aestuarii. The Nitrosospira-like lineages were the main inhabitants of this environment and showed higher diversity with four subclades. Sequences in Clade NsA were grouped with those from Jiaozhou Bay (Dang et al. 2010) and from deep-sea sediments in Japan (Hayashi et al. 2007) and was comprised mostly by sequences
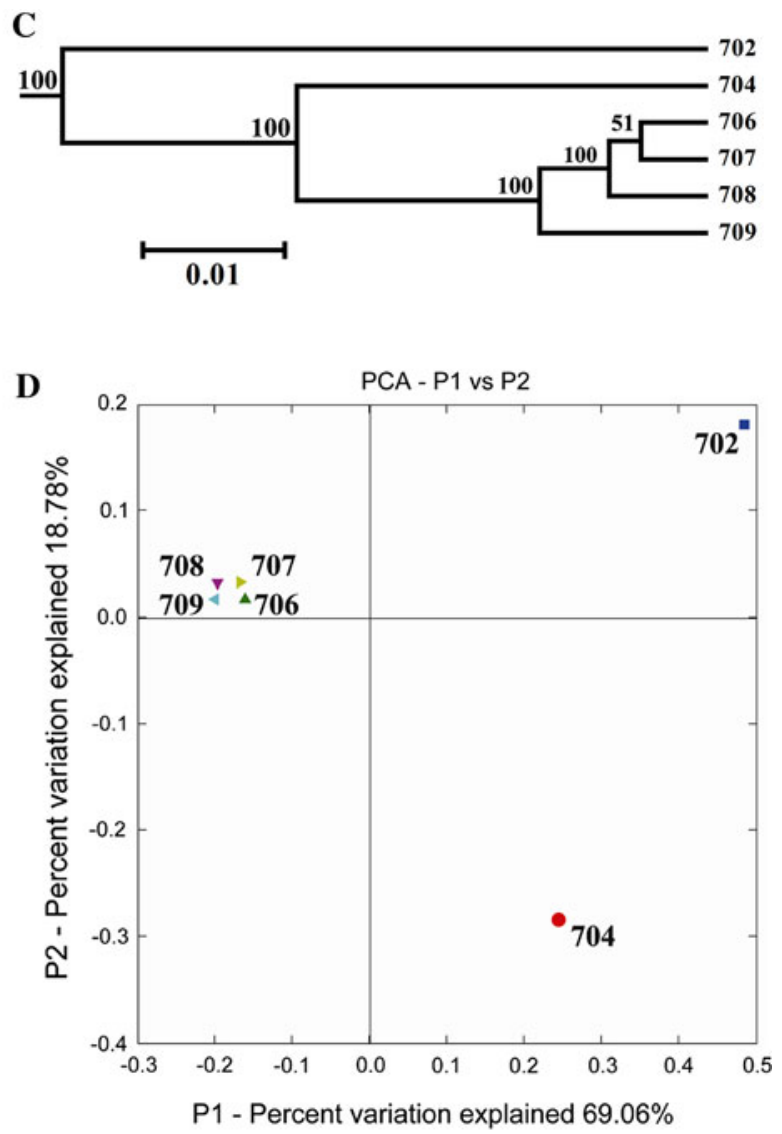

UniFrac software. a and c represent of the Jackknife Environment Clusters trees separately for AOA and betaAOB. $\mathbf{b}$ and $\mathbf{d}$ show the PCoA separately for AOA and beta$\mathrm{AOB}$

from site 709, with only one sequence from site 704 . Another subclade, Clade NsC, exclusively contained sequences from site 702 grouped with sequences from deep-sea sediments in Japan (Hayashi et al. 2007), Kahouanne Basin sediment (Meyer and Kuever 2008) and deep-sea hydrothermal environments (unpublished) and thus showed deep-sea characteristics. Besides these two subclades, sequences from site 704 comprised of Clade NsB and formed a trifurcation with Clade NsA and Clade $\mathrm{NsC}$ as the intermediate branch of deep-sea sediment sequences and estuarine ones. The fourth subclade was comprised of sequences from all sites except for site 702 and grouped with sequences from Jiaozhou Bay (Dang et al. 2010), deep-sea hydrothermal environments (unpublished), marine sponges (Bayer et al. 2008), coral reef sediment in Hawaii of USA (unpublished). 
Fig. 4 Abundance of amoA gene for AOA and betaAOB observed at the sampling sites. The measurements were performed in triplicate. Error bars represent standard deviations of triplicate analyses

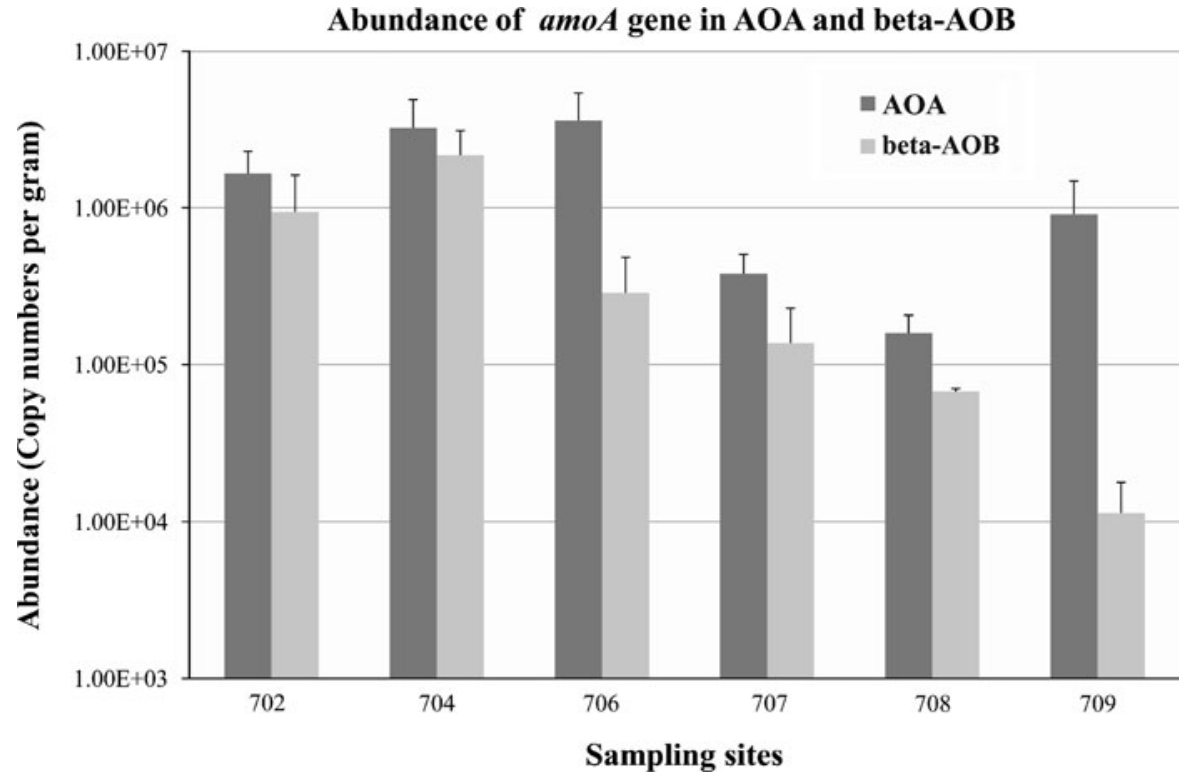

Table 2 Statistical analysis of physicochemical parameters and the diversity and abundance of nitrifying prokaryotes in this study

\begin{tabular}{|c|c|c|c|c|c|c|c|c|c|c|}
\hline \multirow[t]{3}{*}{ Parameter } & \multicolumn{10}{|c|}{ Pearson moment correlation ${ }^{\mathrm{a}}$} \\
\hline & \multicolumn{2}{|l|}{ OUT } & \multicolumn{2}{|c|}{ Shannon Index } & \multicolumn{2}{|c|}{ Simpson Index } & \multicolumn{2}{|l|}{ Chao } & \multicolumn{2}{|c|}{ Abundance } \\
\hline & $\mathrm{AOA}$ & $\mathrm{AOB}$ & $\mathrm{AOA}$ & $\mathrm{AOB}$ & $\mathrm{AOA}$ & $\mathrm{AOB}$ & $\mathrm{AOA}$ & $\mathrm{AOB}$ & $\mathrm{AOA}$ & $\mathrm{AOB}$ \\
\hline Depth & -0.15 & 0.76 & -0.62 & 0.70 & 0.77 & -0.50 & -0.18 & 0.36 & 0.03 & 0.25 \\
\hline $\mathrm{T}$ & -0.14 & $-0.88 *$ & 0.56 & -0.76 & -0.78 & 0.56 & -0.08 & -0.62 & -0.21 & -0.54 \\
\hline $\mathrm{pH}$ & -0.19 & $-0.95 *$ & 0.12 & $-0.96^{*}$ & -0.40 & $0.84 *$ & 0.01 & -0.70 & -0.33 & -0.55 \\
\hline $\mathrm{NH}_{4}^{+}$ & -0.52 & -0.42 & -0.19 & -0.26 & 0.05 & 0.07 & -0.47 & -0.41 & -0.49 & -0.41 \\
\hline $\mathrm{NO}_{2}^{-}$ & 0.77 & -0.42 & 0.34 & 0.27 & 0.10 & -0.25 & 0.72 & 0.80 & 0.40 & $0.88^{*}$ \\
\hline $\mathrm{NO}_{3}^{-}+\mathrm{NO}_{2}^{-}$ & 0.41 & 0.39 & 0.08 & 0.34 & 0.29 & -0.39 & 0.34 & 0.63 & 0.22 & 0.67 \\
\hline $\mathrm{NH}_{4}{ }^{+} /\left(\mathrm{NO}_{2}{ }^{-}+\mathrm{NO}_{3}{ }^{-}\right)^{\mathrm{b}}$ & -0.49 & -0.64 & 0.30 & -0.40 & -0.65 & 0.25 & -0.46 & -0.68 & -0.57 & -0.73 \\
\hline
\end{tabular}

a Pearson moment correlation $(r)$ calculated based on the following equation: $r=\frac{n\left(\sum X Y\right)-\left(\sum X\right)\left(\sum Y\right)}{\sqrt{\left[n \sum X^{2}-\left(\sum X\right)^{2}\right]\left[n \sum Y^{2}-\left(\sum Y\right)^{2}\right]}}$. Asterisks indicates $P$ of $<0.05$, could be as significant determined by Excel function TDIST. The $t$ value deduced from the following equation: $t=X \sqrt{\frac{n-2}{\left(1-r^{2}\right)}} \cdot n$ is the number of sampling sites

b Molar ratios between ammonium and oxidized inorganic species (nitrate plus nitrite)

This subclade should be considered as a costal or estuarine lineage since it lacks any sequence from site 702 , the only deep-sea sample.

Community classification of AmoA protein sequences in the gradient of sediments

Both PCoA and the Jackknife Environment Cluster analyses were employed to detect the significant differences in the amoA assemblages (Lozupone et al.
2007). Not only for AOA, but also for beta-AOB, sites 702 and 704 separated from other sites with larger discrepancy, while the other four sites grouped together with higher support values, whilst 709 was separated from the other three sites (Fig. 3).

Abundance of $a m o A$ gene sequences

The abundance of $a m o A$ gene sequences derived from AOA was from $1.59 \times 10^{5}$ to $3.63 \times 10^{6} / \mathrm{gram}$ 
sediment (wet weight) and from $1.14 \times 10^{4}$ to $2.17 \times 10^{6} /$ gram sediment (wet weight) for betaAOB at different sites, without large differences within samples. The highest abundance identified was more than two orders than the lowest one in beta-AOB (the SD shown in the Fig. 4). Generally, the archaeal amoA gene abundance was higher than bacteria at the same sites. However, the AOA/beta-AOB abundance ratio was not high, except at site 709 which showed a notably high value (ca. 80). Moreover, the amoA gene abundance for AOA and beta-AOB showed a gradient from coastal samples to the deep-sea, excluding the archaeal amoA abundance at site 709 .

Relationships between diversity and abundance of $a m o A$ sequences and physicochemical parameters

Temperature and $\mathrm{pH}$ values were indicated to be potentially important contributors to the diversity of bacterial amoA gene abundance, while the concentration of nitrite was related to the abundance of bacterial amoA gene in the present investigated area (Table 2). However, no factor was shown to contribute significantly to the diversity or abundance of the archaeal amoA genes in this study area (Table 2).

\section{Discussion}

A clear shift of both AOA and beta-AOB distribution from the marginal coast to the slope in the deep-sea was evident based on the diversity and phylogenetic analyses. Although the diversity indices of AOA were stable among all samples, differences of archaeal amoA gene assemblages could also be distinguished. For example, sites 706, 707, 708 and 709 were grouped together in the UniFrac analyses and shared some terrestrial characteristics, while site 702 possessed obvious deep-sea marine features. Most of the deep-sea AOA lineages were from sites 702 and 704, while most sequences from other sites formed other subclades close to the estuarial lineages, indicating the niche specificity along the transect of this study. For the beta-AOB, community changes were also obvious, not only judged by the diversity index but also based on the phylogenetic analyses. Most of the sequences were grouped into the Nitrosospira-like clade, while only a few sequences were clustered with the Nitrosomonas-like clade. This type of distribution was also detected in Changjiang estuary and the adjacent East China Sea through analyzing the AOA amoA gene, indicating a strong impact of the Changjiang freshwater discharge on the marine benthic microbial ecosystem (Dang et al. 2008). Here, from the coastal area to the slope in the deepsea, environmental factors may be the driving force to shape the observed distribution pattern for these two types of nitrifying microbes.

Based on correlation analyses, temperature and $\mathrm{pH}$ values are proposed to be potential contributors to the diversity of bacterial amoA genes, while the concentration of nitrite was related to the abundance of bacterial amoA genes (Table 2). However, no noticeable factor could be identified for the diversity or abundance of archaeal amoA genes (Table 2). It was found that $\mathrm{pH}$ value was positively correlated with the diversity of beta-AOB, likely because $\mathrm{pH}$ is an important factor affecting the concentration of ammonia which is the substrate of ammonia monooxygenase. For the temperature effect, it is more likely to be associated with other factors such as depth, even though temperature was proposed to be the driving force to affect the beta-AOB community (Sahan and Muyzer 2008; Tourna et al. 2008; Urakawa et al. 2008). Altogether, this information could provide insights to understand the differences of ammonia monooxygenase between AOA and betaAOB.

Though substantial numbers of sequences for AOA were retrieved from each sediment sample, there was no sequences sharing highest identity with those of the soil/sediment clade, as the sequences were only grouped into the marine water column/ sediment clade. The similar observation that soil/ sediment clade lineages were not retrieved was also reported at deep-sea hydrothermal fields of the Southern Mariana Trough (Kato et al. 2009). One possible explanation is that a bias of our PCR primers resulted in the mismatch with the potential AOA lineages inhabiting in this environment. Other gene markers should be employed to eliminate this possibility, such as the genes for the $16 \mathrm{~S}$ rRNA, nirK (nitrite reductase) (Bartossek et al. 2010), hcd (putative 4-hydroxybutyrate-CoA dehydratase) (Zhang et al. 2010; Offre et al. 2011), accA (acetylCoA carboxylase) or $h b d$ (4-hydroxybutyryl-CoA dehydratase) (Yakimov et al. 2011). However, it is 
plausible that the actual distribution of the AOA were retrieved here. Given the results, there should be some parameters that shape the specific distribution of AOA. On the other hand, some lineages present here might have higher adaptive ability to this special environment than others but further studies are needed to clarify this.

Although the soil/sediment clade was absent in the phylogenetic tree of the archaeal AmoA deduced protein sequences present, two subclades shared much higher identity with those retrieved from marine and estuarine environments than those typically of terrestrial environment represent by soils and hot springs. These two subclades are separately represented by deep-sea related and estuarine sequences and also show some endemic lineages. Most of the archaeal AmoA protein sequences in the deep-sea related subclade (Clade WD) from the present study grouped with those retrieved from the Western Pacific Ocean, e.g., the Deep-Ocean of Northeastern Japan Sea (Nakagawa et al. 2007), especially the tropical West Pacific Continental Margin (Dang et al. 2009) with high identities at the protein level, indicating these lineages might tolerate to a much wider range of environmental conditions in West Pacific or that these environments share some similarity. In addition, a few sequences shared larger genetic distances (with only about $85 \%$ identity) with deep-sea and estuary related subclades, for instance sequences 707A-47, 706A-53, 708A-1, 708A-64, 707A-15, 708A-17, 704A-16, 707A-43. This indicates the endemicity of these AOA lineages in the SCS. In another type of estuarine subclades, most of the sequences were clustered with those from estuaries (Beman and Francis 2006; Dang et al. 2008; Santoro et al. 2008) while most of the sequences still separated from these retrieved from GenBank, especially in Clade WA, indicating the endemicity of the lineages recovered here.

In the phylogenetic tree of bacterial deduced AmoA amino acid sequences, most sequences were grouped in the genus Nitrosospira-like clade, while only 27 sequences were affiliated to the Nitrosomonas-like clade. Moreover, all of the beta-AOB sequences were grouped with those from estuaries, bays or marine sediments, suggesting these are typical marine or estuarine features. In polluted terrestrial environments (away from estuarine regions), the dominant beta-AOB generally is the genus Nitrosomonas (Dang et al. 2010). It seems that Nitrosospira-like lineages may be more adaptable than Nitrosomonas in estuarine areas. Beta-AOB communities at sampling sites with a strong marine influence were dominated by Nitrosospira clusterlike sequences and those with a strong freshwater influence were dominated by Nitrosomonas oligotropha-like sequences (Freitag et al. 2006). All of the beta-AOB lineages presented here showed large distances from Nitrosomonas oligotropha like lineages (Fig. 2).

The presence of ammonia-oxidizing prokaryotes in the SCS continental margin suggests they may play important roles from the continental shelf to the slope in the deep-sea because the former is adjacent to the Pearl River estuary, which receives a high loading of anthropogenic nutrients in the river discharge. The community changes of AOA and beta-AOB detected in the present study should advance our understanding about the contributors to the nitrogen transformation process in this area. Studies have shown that the archaeal diversity in estuaries might be greater than that in the adjacent open oceans due to terrestrial inputs (Llyd and Jody 2003). For the AOA lineages, some studies have proposed that those in terrestrial environments are distinct from those in marine environments while other studies have indicated that estuaries might harbor mixed populations from soil/ sediment and marine water column/sediment AOA lineages (Dang et al. 2008; Mosier and Francis 2008). The deposition of microbes from the freshwater input could potentially explain the existence of the putative soil-related AOA lineages in the estuarine sedimentary environments. However, in the current study, no obvious soil/sediment-related AOA lineages were present, only estuary and deep-sea related lineages, indicating this area was not strongly affected by the Pearl River discharge. Another study on the total inorganic nitrogen concentration in this area indicated that the sampling sites had reduced inorganic nitrogen influence from the Pearl River estuary ( $\mathrm{Li}$ et al. 2007) and this is consistent with the absence of soil/sediment-related archaeal amoA observed. However, the community structure change of ammoniaoxidizing beta-AOB along the transect could reflect environmental conditions in this area.

In summary, community structure shifts of AOA and beta-AOB were detected from the coastal marginal area to the slope in the deep-sea. The OTU 
numbers of amoA in AOA were much more stable than in beta-AOB. Moreover, the diversity of beta$\mathrm{AOB}$ was potentially correlated with $\mathrm{pH}$ values, while no obvious relationships between AOA and physicochemical parameters were detected, indicating beta-AOB responded more variably to transect changes in this environment, as shown with the diversity and richness indices. Thus beta-AOB might be a indicator for environmental changes. Spatial patterns of these nitrifying microbes and some physicochemical parameters that potentially influence their diversity and distribution are proposed. Besides these, endemic AOA and beta-AOB phylotypes existed in our research area.

The GenBank accession numbers for the amoA gene sequences reported in this study are JF923943 to JF924293 and JF924294 to JF924519 for AOA and $\mathrm{AOB}$, respectively.

Acknowledgments This research was supported by a $\mathrm{PhD}$ studentship (H-L C) from The University of Hong Kong and in part by grants from Agriculture, Fisheries and Conservation Department of the Hong Kong SAR Government (J-DG), and National Natural Science Foundation of China (41076095), Knowledge Innovation Key Project of the Chinese Academy of Sciences (KZCX2-YW-QN207) (Y-GH). We would like to thank Ms. Jessie Lai and Dr Zhenye Zhao for their kindly laboratory assistances throughout this investigation at The University of Hong Kong.

Open Access This article is distributed under the terms of the Creative Commons Attribution Noncommercial License which permits any noncommercial use, distribution, and reproduction in any medium, provided the original author(s) and source are credited.

\section{References}

Bartossek R, Nicol GW, Lanzen A, Klenk HP, Schleper C (2010) Homologues of nitrite reductases in ammoniaoxidizing archaea: diversity and genomic context. Environ Microbiol 12:1075-1088

Bayer K, Schmitt S, Hentschel U (2008) Physiology, phylogeny and in situ evidence for bacterial and archaeal nitrifiers in the marine sponge Aplysina aerophoba. Environ Microbiol 10:2942-2955

Beman JM, Francis CA (2006) Diversity of ammonia-oxidizing archaea and bacteria in the sediments of a hypernutrified subtropical estuary: Bahia del Tobari, Mexico. Appl Environ Microbiol 72:7767-7777

Bernhard AE, Landry ZC, Blevins A, Torre JR, Giblin AE, Stahl D (2010) Abundance of ammonia-oxidizing archaea and bacteria along an estuarine salinity gradient in relation to potential nitrification rates. Appl Environ Microbiol 76:1285-1289

Caffrey JM, Bano N, Kalanetra K, Hollibaugh JT (2007) Ammonia oxidation and ammonia-oxidizing bacteria and archaea from estuaries with differing histories of hypoxia. ISME J 1:660-662

Cai H, Jiao N (2008) Diversity and abundance of nitrate assimilation genes in the northern South China Sea. Microb Ecol 56:751-764

Callahana J, Dai M, Chen R, Li X, Lu Z, Huang W (2004) Distribution of dissolved organic matter in the Pearl River estuary. China Mar Chem 89:211-224

Cao H, Li M, Dang H, Gu J-D (2011a) Responses of aerobic and anaerobic ammonia/ammonium oxidizing microorganisms to anthropogenic pollution in coastal marine environments. In: Klotz MG, Stein LY (eds) Methods in enzymology, vol 496, Part B: Research on nitrification and related processes. Academic Press, New York, pp 35-62

Cao H, Li M, Hong Y, Gu J-D (2011b) Diversity and abundance of ammonia-oxidizing archaea (AOA) and bacteria (AOB) in polluted mangrove sediment. Syst Appl Microbiol. doi:10.1016/j.syapm.2010.11.023

Chen XP, Zhu YG, Xia Y, Shen JP, He JZ (2008) Ammoniaoxidizing archaea: important players in paddy rhizosphere soil? Environ Microbiol 10:1978-1987

Coolen MJ, Abbas B, van Bleijswijk J, Hopmans EC, Kuypers MM, Wakeham SG, Sinninghe Damste JS (2007) Putative ammonia-oxidizing Crenarchaeota in suboxic waters of the Black Sea: a basin-wide ecological study using $16 \mathrm{~S}$ ribosomal and functional genes and membrane lipids. Environ Microbiol 9:1001-1016

Dang H, Zhang X, Sun J, Li T, Zhang Z, Yang G (2008) Diversity and spatial distribution of sediment ammoniaoxidizing crenarchaeota in response to estuarine and environmental gradients in the Changjiang estuary and East China Sea. Microbiology 154:2084-2095

Dang H, Li J, Zhang X, Li T, Tian F, Jin W (2009) Diversity and spatial distribution of amoA-encoding archaea in the deep-sea sediments of the tropical West Pacific Continental Margin. J Appl Microbiol 106:1482-1493

Dang H, Li J, Chen R, Wang L, Guo L, Zhang Z, Klotz MG (2010) Diversity, abundance, and spatial distribution of sediment ammonia-oxidizing betaproteobacteria in response to environmental gradients and coastal eutrophication in Jiaozhou Bay, China. Appl Environ Microbiol 76:4691-4702

Francis CA, Roberts KJ, Beman JM, Santoro AE, Oakley BB (2005) Ubiquity and diversity of ammonia-oxidizing archaea in water columns and sediments of the ocean. Proc Natl Acad Sci USA 102:14683-14688

Freitag TE, Chang L, Prosser JI (2006) Changes in the community structure and activity of betaproteobacterial ammonia-oxidizing sediment bacteria along a freshwatermarine gradient. Environ Microbiol 8:684-696

Hayashi T, Kaneko R, Tanahashi M, Naganuma T (2007) Molecular diversity of the genes encoding ammonia monooxygenase and particulate methane monooxygenase from deep-sea sediments. Res J Microbiol 2:530-537

Huang X, Huang L, Yue W (2003) The characteristics of nutrients and eutrophication in the Pearl River estuary, South China. Mar Pollut Bull 47:30-36 
Kato S, Kobayashi C, Kakegawa T, Yamagishi A (2009) Microbial communities in iron-silica-rich microbial mats at deep-sea hydrothermal fields of the Southern Mariana Trough. Environ Microbiol 11:2094-2111

Lam P, Jensen MM, Lavik G, McGinnis DF, Muller B, Schubert CJ, Amann R, Thamdrup B, Kuypers MM (2007) Linking crenarchaeal and bacterial nitrification to anammox in the Black Sea. Proc Natl Acad Sci USA 104:7104-7109

Li XB, Chen CQ, Shi P, Li X (2007) Retrieval of total inorganic nitrogen concentration in Pearl River estuary by remote sensing. Acta Sci Circum 27:313-318

Li M, Cao H, Hong Y, Gu J-D (2011) Spatial distribution and abundance of ammonia-oxidizing archaea (AOA) and ammonia-oxidizing bacteria (AOB) in mangrove sediments. Appl Microbiol Biotechnol 89:1243-1254

Llyd EW, Jody WD (2003) Abundance of bacteria, the Cytophaga-Flavobacterium cluster and archaea in cold oligotrophic waters and nepheloid layers of the Northwest Passage, Canadian Archipelago. Aquat Microb Ecol 31:19-31

Lozupone C, Hamady M, Knight R (2006) UniFrac_an online tool for comparing microbial community diversity in a phylogenetic context. BMC Bioinform 7:371

Lozupone CA, Hamady M, Kelley ST, Knight R (2007) Quantitative and qualitative beta diversity measures lead to different insights into factors that structure microbial communities. Appl Environ Microbiol 73:1576-1585

Meyer B, Kuever J (2008) Phylogenetic diversity and spatial distribution of the microbial community associated with the Caribbean deep-water sponge Polymastia cf. corticata by $16 \mathrm{~S}$ rRNA, aprA, and amoA gene analysis. Microb Ecol 56:306-321

Mosier AC, Francis CA (2008) Relative abundance and diversity of ammonia-oxidizing archaea and bacteria in the San Francisco Bay estuary. Environ Microbiol 10:3002-3016

Nakagawa T, Mori K, Kato C, Takahashi R, Tokuyama T (2007) Distribution of cold-adapted ammonia-oxidizing microorganisms in the deep-ocean of the northeastern Japan Sea. Microbes Environ 22:365-372

Offre P, Nicol GW, Prosser JI (2011) Community profiling and quantification of putative autotrophic thaumarchaeal communities in environmental samples. Environ Microbiol Rep. doi:10.1111/j.1758-2229.2010.00217.x

Sahan E, Muyzer G (2008) Diversity and spatio-temporal distribution of ammonia-oxidizing archaea and bacteria in sediments of the Westerschelde estuary. FEMS Microbiol Ecol 64:175-186

Santoro AE, Francis CA, de Sieyes NR, Boehm AB (2008) Shifts in the relative abundance of ammonia-oxidizing bacteria and archaea across physicochemical gradients in a subterranean estuary. Environ Microbiol 10:1068-1079

Schleper C, Jurgens G, Jonuscheit M (2005) Genomic studies of uncultivated archaea. Nat Rev Microbiol 3:479-488

Schloss PD, Handelsman J (2006) Introducing SONS, a tool for operational taxonomic unit-based comparisons of microbial community memberships and structures. Appl Environ Microbiol 72:6773-6779

Singh SK, Verma P, Ramaiah N, Anil AC, Shouche YS (2010) Phylogenetic diversity of archaeal 16S rRNA and ammonia monooxygenase genes from tropical estuarine sediments on the central west coast of India. Res Microbiol 161:177-186

Tamura K, Dudley J, Nei M, Kumar S (2007) MEGA4: molecular evolutionary genetics analysis (MEGA) software version 4.0. Mol Biol Evol 24:1596-1599

Tourna M, Freitag TE, Nicol GW, Prosser JI (2008) Growth, activity and temperature responses of ammonia-oxidizing archaea and bacteria in soil microcosms. Environ Microbiol 10:1357-1364

Urakawa H, Tajima Y, Numata Y, Tsuneda S (2008) Low temperature decreases the phylogenetic diversity of ammonia-oxidizing archaea and bacteria in aquarium biofiltration systems. Appl Environ Microbiol 74:894-900

Venter JC, Remington K, Heidelberg JF, Halpern AL, Rusch D, Eisen JA, Wu D, Paulsen I, Nelson KE, Nelson W, Fouts DE, Levy S, Knap AH, Lomas MW, Nealson K, White O, Peterson J, Hoffman J, Parsons R, Baden-Tillson H, Pfannkoch C, Rogers YH, Smith HO (2004) Environmental genome shotgun sequencing of the Sargasso Sea. Science 304:66-74

Wang S, Xiao X, Jiang L, Peng X, Zhou H, Meng J, Wang F (2009) Diversity and abundance of ammonia-oxidizing archaea in hydrothermal vent chimneys, Juan de Fuca Ridge. Appl Environ Microbiol 75:4216-4220

Wankel SD, Mosier AC, Hansel CM, Paytan A, Francis CA (2011) Spatial variability in nitrification rates and ammonia-oxidizing microbial communities in the agriculturally impacted Elkhorn Slough estuary, California. Appl Environ Microbiol 77:269-280

Yakimov MM, Cono VL, Smedile F, Deluca TH, Jurez S, Ciordia S, Fernndez M, Albar JP, Ferrer M, Golyshin PN, Giuliano L (2011) Contribution of crenarchaeal autotrophic ammonia oxidizers to the dark primary production in Tyrrhenian deep waters (Central Mediterranean Sea). ISME J 5:945-961

Zhang LM, Offre PR, He JZ, Verhamme DT, Nicol GW, Prosser JI (2010) Autotrophic ammonia oxidation by soil thaumarchaea. Proc Natl Acad Sci USA 107:17240-17245 